\title{
A glimpse of the ERM proteins
}

\author{
Godwin A. Ponuwei ${ }^{1,2}$
}

\begin{abstract}
In all eukaryotes, the plasma membrane is critically important as it maintains the architectural integrity of the cell. Proper anchorage and interaction between the plasma membrane and the cytoskeleton is critical for normal cellular processes. The ERM (ezrin-radixin-moesin) proteins are a class of highly homologous proteins involved in linking the plasma membrane to the cortical actin cytoskeleton. This review takes a succinct look at the biology of the ERM proteins including their structure and function. Current reports on their regulation that leads to activation and deactivation was examined before taking a look at the different interacting partners. Finally, emerging roles of each of the ERM family members in cancer was highlighted.
\end{abstract}

Keywords: Ezrin, Radixin, Moesin, Plasma membrane, Phospholipids, Cancer

\section{Review}

The ERM proteins are evolutionary conserved group of three related proteins (ezrin, radixin and moesin) that possess band Four point one (4.1) as a common origin [1]. They interact with the plasma membrane through a common FERM (Four point one, ERM) domain [2]. The ERM proteins are located in cellular structures such as filopodia, lamellipodia, apical microvilli, ruffling membranes, cleavage furrow of mitotic cells, retraction fibres, and adhesion sites, where the plasma membrane interacts with F-actin [3]. ERMs are critical for structural stability and for maintaining the integrity of the cell cortex by coupling transmembrane proteins to the actin cytoskeleton [1]. These proteins also play very pivotal intracellular scaffolding roles that aid signal transduction between the intracellular and extracellular compartments of the cell as well as interacting with other membrane phospholipids [4]. Thus, ERMs are involved in regulating several cellular processes including reorganization of actin cytoskeleton, cell survival, membrane dynamics, cell migration, adhesion and regulation of membrane protrusion $[4,5]$.

\footnotetext{
Correspondence: gponuwei4real@yahoo.com
${ }^{1}$ Cell migration laboratory, Molecular and Cellular Medicine Unit, Department

Correspondence: gponuwei4real@yahoo.com
${ }^{1}$ Cell migration laboratory, Molecular and Cellular Medicine Unit, Department of Biomedical Sciences, School of Biological Sciences, Hopkins Building, University of Reading, Whiteknights, Berkshire, UK

${ }^{2}$ Molecular and Cellular Medicine unit, Department of Biomedical sciences, School of Life Sciences, Hopkins Building, Whiteknights Campus, University of Reading, Reading, Berkshire, UK
} () Biomed Central

(c) 2016 Ponuwei. Open Access This article is distributed under the terms of the Creative Commons Attribution 4.0 International License (http://creativecommons.org/licenses/by/4.0/), which permits unrestricted use, distribution, and reproduction in any medium, provided you give appropriate credit to the original author(s) and the source, provide a link to the Creative Commons license, and indicate if changes were made. The Creative Commons Public Domain Dedication waiver (http://creativecommons.org/publicdomain/zero/1.0/) applies to the data made available in this article, unless otherwise stated.

\section{Background \\ Structure of ERM proteins}

Structurally, at the amino terminus of ERM proteins is an approximately 1-296 amino acid FERM domain also known as N-terminal ERM association domain (NERMAD) through which they interact with cell membranes. X-ray crystallography revealed that the FERM domain consists of F1, F2 and F3, also respectively referred to as A, B and C subdomains that fold and joined together to form an cloverleaf structure, and these subdomains are homologous to ubiquitin, acyl-CoA binding protein and plekstrin homology domains respectively $[4,5]$ (Fig. 1). The FERM region is closely flanked by a central (approximately 200 amino acid) $\alpha$-helical domain that form coiled coils [4] and mediate interaction with protein kinase A (PKA) [6]. The carboxylic terminal tail consists of 107 residues, and this terminus contains the F-actin binding site through which ERMs interact with the actin cytoskeleton [7]. In all ERM family members, distinct domains within the $\mathrm{N}$-terminal head and $\mathrm{C}$-terminal tail known as $\mathrm{N}$ - and $\mathrm{C}$-ezrin-radixin-moesin association domains (N-ERMAD and C-ERMAD respectively) mediates homotypic and heterotypic head-to-tail interaction $[4,8,9]$. The N-ERMAD is distinct from the C-ERMAD in that it is a labile domain that is inactivated by chemical agents such as sodium dodecyl sulfate (SDS) treatment, and its activity is negatively affected by freeze thawing, whereas the C-ERMAD is unaffected by chemical treatment [10].

ERMs exist in a dormant, inactive closed conformation within the cytosol in which the C-ERMAD stretches 


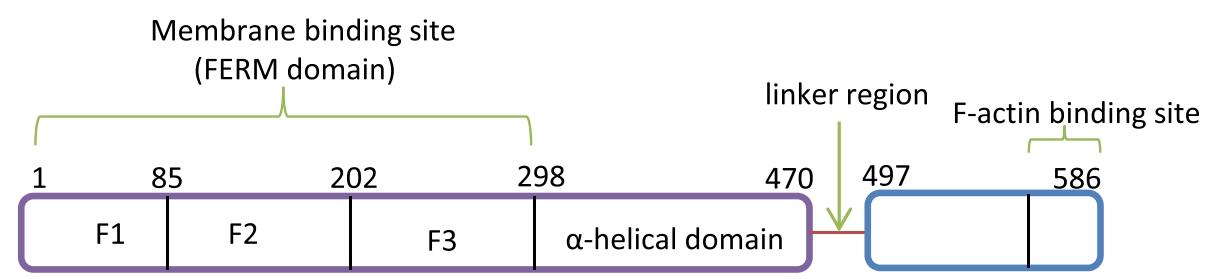

Fig. 1 Basic Structure of ERM Proteins. All ERM proteins possess similar domain structure with the N terminus having F1, F2 and F3 subdomains. At the central portion of the protein is an a-helical domain which is followed by a linker region. At the last 30 carboxyl terminal end is the F-actin binding site

from the F-actin binding site through F2 and F3 to part of the FERM region, thereby concealing both the F-actin and the membrane binding sites from other binding partners $[7,10,11]$. This covering of FERM by the CERMAD is bolstered by the central $\alpha$-helical domain in that it binds the FERM domain to facilitate masking of both domains [4]. Activation of ERMs requires opening up the binding sites in the FERM domain and those of the $\mathrm{F}$-actin biding sites in the $\mathrm{C}$-terminal domain. This is achieved by phosphatidylinositol 4,5-bisphosphate $\left(\mathrm{PIP}_{2}\right)$-mediated uncoupling of the C-terminal domain from the FERM domain [1].

\section{Regulation of ERM proteins}

ERM proteins function is regulated by a two-step process of open (active) and closed (inactive) conformation [12]. They are mainly regulated through conformational changes induced by phospholipids and kinasesmediated phosphorylation, and this results in activation of the proteins [13]. Recruitment of ERMs to areas of the plasma membrane containing high amount of phosphoinositides such as $\mathrm{PIP}_{2}$ exposes a conserved regulatory threonine phosphorylation residue (T567, T564 and T558 in ezrin, radixin and moesin respectively) located in the C-ERMAD domain [14], and this induces a successive activation mechanism whereby $\mathrm{PIP}_{2}$ first bind to a subdomain in the N-terminal FERM domain followed by plasma membrane translocation and phosphorylation of the threonine residues [15]. There are three lysinerich consensus sites known to bind phosphoinositides on the FERM domain of ERM proteins and mutation on any of these sites inhibited $\mathrm{PIP}_{2}$-ERM interaction and translocation to the plasma membrane [16]. PIP $_{2}$-mediated recruitment of ERMs to the plasma membrane is sufficient not only in the phosphorylation of these proteins by other kinases, but also in the formation of microvilli [17].

Phosphorylation of the conserved threonine residue can be induced by different signaling protein kinases such as Rho-associated protein kinase (ROCK), myotonic dystrophy kinase-related Cdc42-binding kinase, G-protein coupled receptor kinase 2, Nck interacting kinase $[14,18-20]$, protein kinase $\mathrm{C}(\mathrm{PKC} \alpha, \mathrm{PKC} \beta)$,
NFKB-inducing kinase (NIK), lymphocyte-oriented kinase (LOK) thereby creating stearic hindrance that keeps the FERM and C-ERMAD domains apart [11, 21-23], and this stabilizes the active state of ERM proteins in their open conformation [15, 17]. Ezrin can be phosphorylated by cyclic-dependent kinase 5 (CDK5) on threonine 235 which lies between the FERM and C-ERMAD domains, and mutation of this site facilitated ezrin localization to plasma membrane [24].

Binding of ERM proteins to the cytoskeleton in many cases is strengthened by phosphorylation of the proteins [25]. Activation of the small Rho GTPase, RhoA and not Rac or Cdc42 was able to induce phosphorylation of both radixin and moesin, and this paralleled formation of membrane protrusions in Swiss 3 T3 cells [26]. Also upon activation of platelets with thrombin, the phosphorylation status of moesin on threonine 558 (a residue also phosphorylated by $\mathrm{PKC} \theta$ ) was enhanced and this bolstered the interaction of moesin with the cytoskeleton, and moesin was found localized at the spreading filopodia [27]. Phosphorylation of radixin on threonine 564 at the C-terminal half by Rho-kinase had no effect on the C-ERMAD to bind F-actin, but attenuated the ability of the C-ERMAD to bind N-ERMAD [28] suggesting that the activated state of ERM proteins during which the intramolecular interaction between the $\mathrm{N}$ - and C-terminal domains is inhibited, can be sustained by the phosphorylation of threonine 564 in radixin [25], threonines 558 and 567 in moesin and ezrin respectively [29].

ERM proteins can also be phosphorylated by receptor tyrosine kinases. Epidermal growth factor (EGF) receptor can phosphorylate ezrin at tyrosines 145 and 353 (Y145 and Y353) [30]. In epithelial kidney cells, Y353 phosphorylation is required for not only binding of phosphatidylinositol 3-kinase to ezrin, but for the activation of Akt signaling pathway [31]. Similarly, stimulation of ezrin-transfected LLC-PK1 cells with hepatocyte growth factor (HGF) resulted in increased phosphorylation of ezrin at the same tyrosine residues and this not only promoted cell migration, but also enhanced intracellular signal transduction [32]. Ezrin Y145 phosphorylation was demonstrated in Jurkat T-cells expressing Lck (a Src family kinase), but not in Lck-deficient cells [33]. 
It is now known that ERM proteins are also activated by sphingolipids. For instance in several cell lines such as A549, HEK, MEF, MCF7 and MDA cells, expression of the bioactive sphingolipid, sphingosine-1-phosphate (S1P) both endogenously and exogenously resulted in phosphorylation and activation of ezrin in a time- and dose-dependent manner [34, 35], and in Hela cells, S1Pmediated phosphorylation was found to be through S1P receptor 2 (S1PR2). This was required for filopodia formation [34]. In a PKC-dependent manner, S1P stimulation of pulmonary endothelial cells resulted in activation of ezrin and moesin, but not radixin [36, 37]. However, contrary to its known functions, via unclear mechanisms, S1P phosphorylation of ezrin resulted in inhibition of cell invasion, and this could be attributed to the ability of S1P to act on different receptors [35]. In Hela cells, generation of plasma membrane ceramide through breakdown of sphingomyelin by the action of sphingomyelinase resulted in dephosphorylation of ERM proteins, while decreasing plasma membrane levels of the sphingolipid resulted in ERM proteins hyperphosphorylation [12].

Regulation of ERM proteins is also brought about by dephosphorylation and inactivation of the proteins through the activities of phosphatases, and via $\mathrm{PIP}_{2}$ hydrolysis. In Hela cells, ceramide drives ERM dephosphorylation through activation of protein phosphatase $1 \alpha(\mathrm{PP} 1 \alpha)$ with the resultant effect of inactivating ERM and subsequent dissociation from the plasma membrane [38]. Similarly, overexpression of the small protein tyrosine phosphatase, phosphatase of regenerating liver-3 (PRL-3) in HCT116 colon cancer cell line resulted in dephosphorylation of ezrin [39]. Moesin can be downregulated by myosin light chain phosphatase through dephosphorylation of threonine 558 [40]. Although, in phorbol 12-myristate 13 acetate (PMA)-stimulated leucocytes, ezrin is inactivated through calpain-mediated cleavage, moesin and radixin are insensitive to cleavage by calpain [41] suggesting that distinct regulatory mechanisms exist for each protein in the same cell.

\section{Interaction of ERMs with other proteins}

There are several proteins within the plasma membrane that interact with activated ERM proteins through the FERM domain. In a manner dependent on $\mathrm{PIP}_{2}$, ERM proteins can associate with the cytoplasmic tails of intracellular adhesion molecules -1, -3 (ICAM-1 and -3) [42] and -2 (ICAM-2), as well as the hyaluronan receptor CD44 and CD43 [43]. ERMs are also known to bind PDZ (postsynaptic density protein)-containing proteins such as transporters and ion channels through other anchoring proteins like NHERF1 $\left(\mathrm{Na}^{+}-\mathrm{H}^{+}\right.$exchanger regulatory factor) also known as ERM-binding phosphoprotein 50 (EBP50) and NHERF2 $[44,45]$. They also interact with membrane glycoproteins such as P-selectin glycoprotein ligand-1 which tether white blood cells to injured tissues [42]. The $\alpha$-helical domain on the central portion of ERMs can also bind subunits of HOPS complex (homotypic fusion and protein sorting) as well as the regulatory subunits RII of protein kinase A [46]. Binding of ERM proteins to PKA tethers it to downstream targets to effect cAMPmediated biological processes such as cell differentiation, proliferation, metabolism, apoptosis, exocytosis, T cell and $\mathrm{B}$ cell activation, muscle contraction [6]. In COS-1 cells, ezrin was shown to bind and link syndecan-2 to the cortical cytoskeleton [47]. The death receptor Fas/CD95, unlike other membrane proteins that bind all ERM proteins, did not bind to moesin but only to ezrin in T lymphocytes [48].

\section{ERM proteins and cancer}

Cancer cell migration is a coordinated process involving different steps that bring about loss of cell-cell adhesion and deregulation of cell-matrix interaction. Several reports have outlined different factors such as localization of ERMs within the cell, their level of phosphorylation as well as expression profile to be responsible for ERM proteins-mediated promotion of tumourigenesis [2]. Below is a brief discussion of each of the ERM proteins, with the aim of highlighting their significance in different human cancers.

\section{Ezrin}

Abnormal localization of ERM proteins is a leading factor resulting aberrant intracellular signal transduction triggered by growth factors. For instance, in breast carcinoma, ezrin which was originally situated at apical structures in normal cell was found translocated to the cytoplasm and plasma membrane and this aberrant localization resulted in the acquisition of an epithelialmesenchymal transition (EMT) in which cells loss their normal differentiated, planar and apical-based polarity and anchorage dependent architecture and instead acquire metastatic phenotype that correlated with poor prognosis [49].

In epithelial cells, interaction of ezrin with Fes kinase causes recruitment and activation of the later at the cell membrane where it facilitates HGF-mediated loss of cell-cell and cell-ECM contacts resulting in cell migration as revealed by wound healing assay $[32,50]$. In this interaction, ezrin not only localized to the leading edge of migrating epithelial cells [50], but also promoted the formation of membrane protrusions [2].

Similarly, upon phosphorylation of the ERM proteins by PKC $\alpha$, ERMs can act as downstream effector of PKC to mediate cell migration when the later was stimulated with phorbol-ester [51]. PKC activation by phorbol ester also caused a switch in phosphorylation site of the 
transmembrane receptor CD44 from Ser325 to Ser29 and this phosphorylation regulated the association of ezrin with CD44 to promote directional cell migration triggered by CD44 [52]. Ezrin binds cell-neural adhesion molecule (L1-CAM) to promote progression of colorectal cancer in that RNA interference of ezrin activity inhibited tumour metastasis mediated by L1-CAM [53]. In 3D matrigel matrix, perturbation of ezrin activity with small hairpin RNA technology reduced the metastatic and invasive capabilities of MDA-MB-231 and MCF10A breast cancer cell lines [54]. Ezrin Y145 phosphorylation in mouse mammary carcinoma cell line SP1 [55] and in pig kidney epithelial LLC-PK1 [56] cells resulted in cell spreading. Elevated expression of ezrin has been reported in LTE, BE1, H446 and H460 lung cancer cell lines, and a substantial decrease in migration, proliferation and invasion was observed upon siRNA-mediated knockdown of ezrin [57]. In high grade prostate cancers, overexpression of ezrin has been reported [58, 59], and this was attributed to increased expression of oncogenic c-Myc [60]. Interestingly, ezrin itself, through a feedback loop involving the Akt/PI3K pathway can regulate cMyc levels and this is crucial for cell migration and invasion [60, 61]. Ezrin overexpression has been shown in other cancer such as pancreatic carcinoma, rhabdomyosarcoma and osteosarcoma [62-64].

\section{Radixin}

Although, much is not known about the role of radixin in cancer, unlike ezrin, however, radixin has been implicated in prostate cancer progression [65]; and impairment of radixin in human pancreatic cancer cell line by shRNA not only significantly attenuated cell proliferation, survival, adhesion and invasion but also enhanced expression levels of the cell-cell adhesion molecule, Ecadherin [66]. In a manner dependent on Vav (a guanine exchange nucleotide factor for Rac1) activity, downregulation of radixin levels resulted in an increase in Rac1 activity [67]. In radixin, phosphorylation of a conserved threonine 564 residue is sufficient to prevent the interaction of the FERM domain at the $\mathrm{N}$-terminus with the F-actin binding domain at the C-ERMAD terminus, and this results in constitutive opening of the membrane and F-actin binding domains [68]. Indeed, in Madin-Darby canine kidney (MDCK) epithelial cells, phosphorylation of radixin on this site (T564) by the G protein-coupled receptor kinase 2 (GRK2) was able to induce membrane protrusions as well as increased migration of the cells as determined by wound healing assay [69]. In contrast to the aforementioned positive roles of radixin in tumourigenesis, a novel role in which the protein appeared to inhibit metastasis has been reported. According to this report, perturbation of radixin activity in the metastatic prostate cancer cell line PC3 by siRNA technology resulted in an elevated increase in spreading of cells, enhanced cell-cell adhesion and acquisition of epithelial phenotype [70].

\section{Moesin}

Expression of moesin has been correlated with increased tumour size and invasive capability, and there was an aberrant trafficking of the protein from plasma membrane to the cytosol in oral squamous carcinoma cell (OSCC) in which moesin was knocked down [71]. Similarly, whereas high grade glioblastoma showed high expression levels of moesin, there was no change in expression levels of ezrin and radixin [72]. Moesin promoted tumour cell invasion in that in vitro 3D cell migration assays revealed that moesin depleted-cells exhibited reduced invasiveness $[61,73]$. Moesin is considered an important promoter of metastasis as it has been shown to induce EMT in human mammary cell MCF10A [74], and there are now emerging reports that moesin is upregulated in different human cancer cell lines $[75,76]$ as well as a marker of EMT [74, $77,78]$. In the same vein, high level of moesin was also found in head and neck squamous cell carcinoma [79]. Whereas both moesin and radixin were found upregulated in lymph node metastases of pancreatic cancer, the level of ezrin expression was unaffected, but its phosphorylation status did change [80].

\section{Conclusion and future perspectives}

ERM proteins play very vital role in maintaining cellular integrity and in mediating signal transduction from different extracellular inputs through their interaction different receptor tyrosine kinases (RTKs) such as EGFR and HGFR, adhesion and adaptor proteins such as Ecadherin, ICAM-1,2,3, NHERF and CD44, and other signaling pathways such as PI3K/Akt, cAMP/PKA and the Rho GTPases, all of which have been implicated in tumorigenesis; thus, making ERM proteins important target in development of novel therapeutics in fighting cancer progression. Although, there are ample reports on involvement of ERMs in cancer, detailed understanding of the mechanisms of their interactions with other proteins as well as their activation is still lacking and requires further investigation.

\section{Abbreviations \\ EGF: Epidermal growth factor; EMT: Epithelial-mesenchymal transition; ERM: Ezrin, radixin, moesin; FERM: Four point one ERM domain; HGF: Hepatocyte growth factor; ICAM: Intracellular adhesion molecule; LOK: Lymphocyte oriented kinase; NHERF: $\mathrm{Na}^{+}-\mathrm{H}^{+}$exchanger regulatory factor; PIP 2 : Phosphatidylinositol 4,5-bisphosphate; PKA/C: Protein kinase A/C; RTKs: Receptor tyrosine kinases; S1P: Sphingosine-1-phosphate.}

Competing interests

The author declare that there are no competing interests.

Authors' contribution

GAP conceptualized and wrote the manuscript. 


\section{Acknowledgements}

Special thanks to Dr. Phil Dash at the Cell migration laboratory, University of Reading, United Kingdom for editing the work.

\section{Received: 13 November 2015 Accepted: 15 February 2016} Published online: 17 March 2016

\section{References}

1. Fehon RG, McClatchey Al, Bretscher A. Organizing the cell cortex: the role of ERM proteins. Nat Rev Mol Cell Biol. 2010;11(4):276-87.

2. Arpin M, Chirivino D, Naba A, Zwaenepoel I. Emerging role for ERM proteins in cell adhesion and migration. Cell Adhes Migr. 2011;5(2):199-206.

3. Wakayama T, Nakata H, Kurobo M, Sai Y, Iseki S. Expression, localization, and binding activity of the ezrin/radixin/moesin proteins in the mouse testis. J Histochem Cytochem. 2009;57(4):351-62.

4. Pore D, Gupta N. The ezrin-radixin-moesin family of proteins in the regulation of B-cell immune response. Crit Rev Immunol. 2015;35(1):15-31.

5. Bretscher A, Edwards K, Fehon RG. ERM proteins and merlin: integrators at the cell cortex. Nat Rev Mol Cell Biol. 2002;3(8):586-99.

6. Dransfield DT, Bradford AJ, Smith J, Martin M, Roy C, Mangeat PH, Goldenring JR. Ezrin is a cyclic AMP-dependent protein kinase anchoring protein. EMBO J. 1997;16(1):35-43.

7. Hamada K, Shimizu T, Yonemura S, Tsukita S, Hakoshima T. Structural basis of adhesion-molecule recognition by ERM proteins revealed by the crystal structure of the radixin-ICAM-2 complex. EMBO J. 2003;22(3):502-14.

8. Algrain $\mathrm{M}$, Turunen $\mathrm{O}$, Vaheri $\mathrm{A}$, Louvard $\mathrm{D}$, Arpin $\mathrm{M}$. Ezrin contains cytoskeleton and membrane binding domains accounting for its proposed role as a membrane-cytoskeletal linker. J Cell Biol. 1993;120(1):129-39.

9. Pore D, Bodo J, Danda A, Yan D, Phillips JG, Lindner D, Hill BT, Smith MR, Hsi ED, Gupta N. Identification of Ezrin-Radixin-Moesin proteins as novel regulators of pathogenic B-cell receptor signaling and tumor growth in diffuse large B-cell lymphoma. Leukemia. 2015;29(9):1857-67.

10. Gary R, Bretscher A. Ezrin self-association involves binding of an N-terminal domain to a normally masked C-terminal domain that includes the F-actin binding site. Mol Biol Cell. 1995;6(8):1061-75.

11. Pearson MA, Reczek D, Bretscher A, Karplus PA. Structure of the ERM protein moesin reveals the FERM domain fold masked by an extended actin binding tail domain. Cell. 2000;101(3):259-70

12. Canals D, Jenkins RW, Roddy P, Hernandez-Corbacho MJ, Obeid LM, Hannun YA. Differential effects of ceramide and sphingosine 1-phosphate on ERM phosphorylation: probing sphingolipid signaling at the outer plasma membrane. J Biol Chem. 2010;285(42):32476-85.

13. Bonilha VL. Focus on molecules: ezrin. Exp Eye Res. 2007;84(4):613-4

14. Nakamura N, Oshiro N, Fukata Y, Amano M, Fukata M, Kuroda S, Matsuura Y, Leung T, Lim L, Kaibuchi K. Phosphorylation of ERM proteins at filopodia induced by Cdc42. Genes Cells. 2000;5(7):571-81.

15. Fievet BT, Gautreau A, Roy C, Del Maestro L, Mangeat P, Louvard D, Arpin M. Phosphoinositide binding and phosphorylation act sequentially in the activation mechanism of ezrin. J Cell Biol. 2004;164(5):653-9.

16. Barret $C$, Roy $C$, Montcourrier $P$, Mangeat $P$, Niggli V. Mutagenesis of the phosphatidylinositol 4,5-bisphosphate (PIP(2)) binding site in the $\mathrm{NH}(2)$ terminal domain of ezrin correlates with its altered cellular distribution. Cell Biol. 2000;151(5):1067-80.

17. Yonemura S, Matsui T, Tsukita S. Rho-dependent and -independent activation mechanisms of ezrin/radixin/moesin proteins: an essential role for polyphosphoinositides in vivo. J Cell Sci. 2002;115(Pt 12):2569-80.

18. Baumgartner M, Sillman AL, Blackwood EM, Srivastava J, Madson N, Schilling JW, Wright JH, Barber DL. The Nck-interacting kinase phosphorylates ERM proteins for formation of lamellipodium by growth factors. Proc Natl Acad Sci U S A. 2006;103(36):13391-6.

19. Cant SH, Pitcher JA. G protein-coupled receptor kinase 2-mediated phosphorylation of ezrin is required for $\mathrm{G}$ protein-coupled receptordependent reorganization of the actin cytoskeleton. Mol Biol Cell. 2005; 16(7):3088-99.

20. Oshiro N, Fukata Y, Kaibuchi K. Phosphorylation of moesin by rho-associated kinase (Rho-kinase) plays a crucial role in the formation of microvilli-like structures. J Biol Chem. 1998;273(52):34663-6.

21. Nakamura F, Huang L, Pestonjamasp K, Luna EJ, Furthmayr H. Regulation of F-actin binding to platelet moesin in vitro by both phosphorylation of threonine 558 and polyphosphatidylinositides. Mol Biol Cell. 1999;10(8):2669-85.
22. Belkina NV, Liu Y, Hao JJ, Karasuyama H, Shaw S. LOK is a major ERM kinase in resting lymphocytes and regulates cytoskeletal rearrangement through ERM phosphorylation. Proc Natl Acad Sci U S A. 2009;106(12):4707-12.

23. Pietromonaco SF, Simons PC, Altman A, Elias L. Protein kinase C-theta phosphorylation of moesin in the actin-binding sequence. J Biol Chem. 1998;273(13):7594-603.

24. Yang HS, Hinds PW. Increased ezrin expression and activation by CDK5 coincident with acquisition of the senescent phenotype. Mol Cell. 2003;11(5):1163-76.

25. Bretscher A. Regulation of cortical structure by the ezrin-radixin-moesin protein family. Curr Opin Cell Biol. 1999;11(1):109-16.

26. Shaw RJ, Henry M, Solomon F, Jacks T. RhoA-dependent phosphorylation and relocalization of ERM proteins into apical membrane/actin protrusions in fibroblasts. Mol Biol Cell. 1998;9(2):403-19.

27. Nakamura F, Amieva MR, Furthmayr H. Phosphorylation of threonine 558 in the carboxyl-terminal actin-binding domain of moesin by thrombin activation of human platelets. J Biol Chem. 1995;270(52):31377-85.

28. Matsui T, Maeda M, Doi Y, Yonemura S, Amano M, Kaibuchi K, Tsukita S. Rho-kinase phosphorylates $\mathrm{COOH}$-terminal threonines of ezrin/radixin/moesin (ERM) proteins and regulates their head-to-tail association. J Cell Biol. 1998;140(3):647-57

29. Ivetic A, Ridley AJ. Ezrin/radixin/moesin proteins and Rho GTPase signalling in leucocytes. Immunology. 2004;112(2):165-76.

30. Krieg J, Hunter T. Identification of the two major epidermal growth factor-induced tyrosine phosphorylation sites in the microvillar core protein ezrin. J Biol Chem. 1992;267(27):19258-65.

31. Gautreau A, Poullet P, Louvard D, Arpin M. Ezrin, a plasma membranemicrofilament linker, signals cell survival through the phosphatidylinositol 3-kinase/Akt pathway. Proc Natl Acad Sci U S A. 1999;96(13):7300-5.

32. Crepaldi T, Gautreau A, Comoglio PM, Louvard D, Arpin M. Ezrin is an effector of hepatocyte growth factor-mediated migration and morphogenesis in epithelial cells. J Cell Biol. 1997;138(2):423-34.

33. Autero M, Heiska L, Ronnstrand L, Vaheri A, Gahmberg CG, Carpen O. Ezrin is a substrate for Lck in T cells. FEBS Lett. 2003;535(1-3):82-6.

34. Gandy KA, Canals D, Adada M, Wada M, Roddy P, Snider AJ, Hannun YA Obeid LM. Sphingosine 1-phosphate induces filopodia formation through S1PR2 activation of ERM proteins. Biochem J. 2013:449(3):661-72.

35. Adada M, Canals D, Hannun YA, Obeid LM. Sphingolipid regulation of ezrin, radixin, and moesin proteins family: implications for cell dynamics. Biochim Biophys Acta. 2014;1841(5):727-37.

36. Adyshev DM, Moldobaeva NK, Elangovan VR, Garcia JG, Dudek SM. Differential involvement of ezrin/radixin/moesin proteins in sphingosine 1-phosphate-induced human pulmonary endothelial cell barrier enhancement. Cell Signal. 2011;23(12):2086-96.

37. Adyshev DM, Dudek SM, Moldobaeva N, Kim KM, Ma SF, Kasa A, Garcia JG, Verin AD. Ezrin/radixin/moesin proteins differentially regulate endothelial hyperpermeability after thrombin. Am J Physiol Lung Cell Mol Physiol. 2013;305(3):L240-55.

38. Canals D, Roddy P, Hannun YA. Protein phosphatase 1alpha mediates ceramide-induced ERM protein dephosphorylation: a novel mechanism independent of phosphatidylinositol 4, 5-biphosphate (PIP2) and myosin/ERM phosphatase. J Biol Chem. 2012;287(13):10145-55

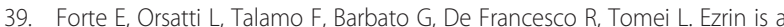
specific and direct target of protein tyrosine phosphatase PRL-3. Biochim Biophys Acta. 2008;1783(2):334-44.

40. Fukata Y, Kimura K, Oshiro N, Saya H, Matsuura Y, Kaibuchi K. Association of the myosin-binding subunit of myosin phosphatase and moesin: dual regulation of moesin phosphorylation by Rho-associated kinase and myosin phosphatase. J Cell Biol. 1998;141(2):409-18.

41. Shcherbina A, Bretscher A, Kenney DM, Remold-O'Donnell E. Moesin, the major ERM protein of lymphocytes and platelets, differs from ezrin in its insensitivity to calpain. FEBS Lett. 1999:443(1):31-6.

42. Wang Z, Schey KL. Aquaporin-0 interacts with the FERM domain of ezrin/ radixin/moesin proteins in the ocular lens. Invest Ophthalmol Vis Sci. 2011;52(8):5079-87.

43. Yonemura S, Hirao M, Doi Y, Takahashi N, Kondo T, Tsukita S. Ezrin/radixin/ moesin (ERM) proteins bind to a positively charged amino acid cluster in the juxta-membrane cytoplasmic domain of CD44, CD43, and ICAM-2. J Cell Biol. 1998;140(4):885-95 
44. Weinman EJ, Hall RA, Friedman PA, Liu-Chen LY, Shenolikar S. The association of NHERF adaptor proteins with g protein-coupled receptors and receptor tyrosine kinases. Annu Rev Physiol. 2006;68:491-505.

45. Reczek D, Berryman M, Bretscher A. Identification of EBP50: A PDZ-containing phosphoprotein that associates with members of the ezrin-radixin-moesin family. J Cell Biol. 1997;139(1):169-79.

46. Chirivino D, Del Maestro L, Formstecher E, Hupe P, Raposo G, Louvard D Arpin M. The ERM proteins interact with the HOPS complex to regulate the maturation of endosomes. Mol Biol Cell. 2011;22(3):375-85.

47. Granes F, Urena JM, Rocamora N, Vilaro S. Ezrin links syndecan-2 to the cytoskeleton. J Cell Sci. 2000;113(Pt 7):1267-76

48. Parlato S, Giammarioli AM, Logozzi M, Lozupone F, Matarrese P, Luciani F, Falchi M, Malorni W, Fais S. CD95 (APO-1/Fas) linkage to the actin cytoskeleton through ezrin in human T lymphocytes: a novel regulatory mechanism of the CD95 apoptotic pathway. EMBO J. 2000;19(19):5123-34.

49. Sarrio D, Rodriguez-Pinilla SM, Dotor A, Calero F, Hardisson D, Palacios J. Abnormal ezrin localization is associated with clinicopathological features in invasive breast carcinomas. Breast Cancer Res Treat. 2006;98(1):71-9.

50. Naba A, Reverdy C, Louvard D, Arpin M. Spatial recruitment and activation of the Fes kinase by ezrin promotes HGF-induced cell scattering. EMBO J. 2008;27(1):38-50.

51. Ng T, Parsons M, Hughes WE, Monypenny J, Zicha D, Gautreau A, Arpin M, Gschmeissner S, Verveer PJ, Bastiaens PI, et al. Ezrin is a downstream effector of trafficking PKC-integrin complexes involved in the control of cell motility. EMBO J. 2001;20(11):2723-41.

52. Legg JW, Lewis CA, Parsons M, Ng T, Isacke CM. A novel PKC-regulated mechanism controls CD44 ezrin association and directional cell motility. Nat Cell Biol. 2002;4(6):399-407.

53. Gavert N, Ben-Shmuel A, Lemmon V, Brabletz T, Ben-Ze'ev A. Nuclear factor-kappaB signaling and ezrin are essential for L1-mediated metastasis of colon cancer cells. J Cell Sci. 2010;123(Pt 12):2135-43.

54. Konstantinovsky S, Davidson B, Reich R. Ezrin and BCAR1/p130Cas mediate breast cancer growth as 3-D spheroids. Clin Exp Metastasis. 2012;29(6):527-40

55. Elliott BE, Qiao H, Louvard D, Arpin M. Co-operative effect of c-Src and ezrin in deregulation of cell-cell contacts and scattering of mammary carcinoma cells. J Cell Biochem. 2004;92(1):16-28.

56. Srivastava J, Elliott BE, Louvard D, Arpin M. Src-dependent ezrin phosphorylation in adhesion-mediated signaling. Mol Biol Cell. 2005:16(3):1481-90.

57. Li Q, Gao H, Xu H, Wang X, Pan Y, Hao F, Qiu X, Stoecker M, Wang E. Expression of ezrin correlates with malignant phenotype of lung cancer, and in vitro knockdown of ezrin reverses the aggressive biological behavior of lung cancer cells. Tumour Biol. 2012;33(5):1493-504.

58. Valdman A, Fang X, Pang ST, Nilsson B, Ekman P, Egevad L. Ezrin expression in prostate cancer and benign prostatic tissue. Eur Urol. 2005:48(5):852-7.

59. Pang ST, Fang X, Valdman A, Norstedt G, Pousette A, Egevad L, Ekman P. Expression of ezrin in prostatic intraepithelial neoplasia. Urology. 2004;63(3):609-12

60. Chuan YC, Iglesias-Gato D, Fernandez-Perez L, Cedazo-Minguez A, Pang ST, Norstedt G, Pousette A, Flores-Morales A. Ezrin mediates c-Myc actions in prostate cancer cell invasion. Oncogene. 2010;29(10):1531-42.

61. Clucas J, Valderrama F. ERM proteins in cancer progression. J Cell Sci. 2015;128(6):1253.

62. Hunter KW. Ezrin, a key component in tumor metastasis. Trends Mol Med. 2004;10(5):201-4.

63. Meng Y, Lu Z, Yu S, Zhang Q, Ma Y, Chen J. Ezrin promotes invasion and metastasis of pancreatic cancer cells. J Transl Med. 2010;8:61.

64. Shang $X$, Wang $Y$, Zhao Q, Wu K, Li X, Ji X, He R, Zhang W. siRNAs target sites selection of ezrin and the influence of RNA interference on ezrin expression and biological characters of osteosarcoma cells. Mol Cell Biochem. 2012;364(1-2):363-71.

65. Bartholow TL, Chandran UR, Becich MJ, Parwani AV. Immunohistochemical staining of radixin and moesin in prostatic adenocarcinoma. BMC Clin Pathol. 2011;11:1.

66. Chen SD, Song MM, Zhong ZQ, Li N, Wang PL, Cheng S, Bai RX, Yuan HS. Knockdown of radixin by RNA interference suppresses the growth of human pancreatic cancer cells in vitro and in vivo. Asian Pac J Cancer Prev. 2012;13(3):753-9.
67. Abe K, Rossman KL, Liu B, Ritola KD, Chiang D, Campbell SL, Burridge K, Der CJ. Vav2 is an activator of Cdc42, Rac1, and RhoA. J Biol Chem. 2000;275(14):10141-9.

68. Louvet-Vallee S. ERM proteins: from cellular architecture to cell signaling. Biol Cell. 2000;92(5):305-16.

69. Kahsai AW, Zhu S, Fenteany G. G protein-coupled receptor kinase 2 activates radixin, regulating membrane protrusion and motility in epithelial cells. Biochim Biophys Acta. 2010;1803(2):300-10.

70. Valderrama F, Thevapala S, Ridley AJ. Radixin regulates cell migration and cell-cell adhesion through Rac1. J Cell Sci. 2012;125(Pt 14):3310-9.

71. Kobayashi H, Sagara J, Kurita H, Morifuji M, Ohishi M, Kurashina K, Taniguchi S. Clinical significance of cellular distribution of moesin in patients with oral squamous cell carcinoma. Clin Cancer Res. 2004;10(2):572-80.

72. Zhu X, Morales FC, Agarwal NK, Dogruluk T, Gagea M, Georgescu MM. Moesin is a glioma progression marker that induces proliferation and Wnt/beta-catenin pathway activation via interaction with CD44. Cancer Res. 2013;73(3):1142-55.

73. Estecha A, Sanchez-Martin L, Puig-Kroger A, Bartolome RA, Teixido J, Samaniego $\mathrm{R}$, Sanchez-Mateos P. Moesin orchestrates cortical polarity of melanoma tumour cells to initiate 3D invasion. J Cell Sci. 2009;122(Pt 19):3492-501.

74. Haynes J, Srivastava J, Madson N, Wittmann T, Barber DL. Dynamic actin remodeling during epithelial-mesenchymal transition depends on increased moesin expression. Mol Biol Cell. 2011;22(24):4750-64.

75. Charafe-Jauffret E, Monville F, Bertucci F, Esterni B, Ginestier C, Finetti P, Cervera N, Geneix J, Hassanein M, Rabayrol L, et al. Moesin expression is a marker of basal breast carcinomas. Int J Cancer. 2007;121(8):1779-85.

76. Condeelis J, Singer RH, Segall JE. The great escape: when cancer cells hijack the genes for chemotaxis and motility. Annu Rev Cell Dev Biol. 2005;21:695-718.

77. Abiatari I, Esposito I, Oliveira TD, Felix K, Xin H, Penzel R, Giese T, Friess H, Kleeff J. Moesin-dependent cytoskeleton remodelling is associated with an anaplastic phenotype of pancreatic cancer. J Cell Mol Med. 2010;14(5):1166-79.

78. Wang CC, Liau JY, Lu YS, Chen JW, Yao YT, Lien HC. Differential expression of moesin in breast cancers and its implication in epithelial-mesenchymal transition. Histopathology. 2012;61(1):78-87.

79. Belbin TJ, Singh B, Smith RV, Socci ND, Wreesmann VB, Sanchez-Carbayo M, Masterson J, Patel S, Cordon-Cardo C, Prystowsky MB, et al. Molecular profiling of tumor progression in head and neck cancer. Arch Otolaryngol Head Neck Surg. 2005;131(1):10-8.

80. Cui Y, Wu J, Zong M, Song G, Jia Q, Jiang J, Han J. Proteomic profiling in pancreatic cancer with and without lymph node metastasis. Int J Cancer. 2009;124(7):1614-21.

\section{Submit your next manuscript to BioMed Central and we will help you at every step:}

- We accept pre-submission inquiries

- Our selector tool helps you to find the most relevant journal

- We provide round the clock customer support

- Convenient online submission

- Thorough peer review

- Inclusion in PubMed and all major indexing services

- Maximum visibility for your research

Submit your manuscript at www.biomedcentral.com/submit
Biomed Central 